\title{
The Development of Ecological Economics Research in China \\ Yang Haoran
}

Qinghai Provincial Party School, Qinghai Xining 810001.

\section{Keywords: Ecological economics; expansion; China}

\begin{abstract}
China has made great progress in theory and practice after more than 30 years of development. With the arrival of the new era, the development of China's development concept and mode has undergone profound changes, and new development requirements for theoretical research have been put forward. This paper focuses on the current situation of economic and social practice and ecological economics theory in China, guided by practice and problem-oriented, and discusses the research scope, research theme and research content of ecological economics in China, so as to try to expand the research system of ecological economics in China.
\end{abstract}

\section{中国生态经济学研究的拓展}

\author{
杨皓然
}

中共青海省委党校，青海 西宁 810001

关键词: 生态经济学; 拓展; 中国

摘要: 中国生态经济学作为新兴学科, 经过 30 余年的发展取得了理论与实践的长足进步。随着新时 代的到来, 中国发展理念、方式发展均发生了深刻变化, 对理论研究提出新的发展要求。本文紧紧围 绕中国经济社会实践活动和生态经济学理论研究现状, 以实践为指引, 以问题为导向, 对中国生态经 济学研究范畴、研究主题和研究内容等方面展开讨论, 以尝试拓展中国生态经济学研究体系。

\section{1.前言}

生态经济学是研究经济系统与生态系统之间相互制约与相互作用的经济学分支学科。作 为一门新兴的社会科学, 它是由自然科学的生态学和社会科学的经济学交叉结合形成。在国 外, 它产生于 20 世纪 60 年代, 相比较经济学、生态学等相邻学科较为年轻。在中国, 它兴 起于 20 世纪 80 年代初, 已走过 30 余年。中国学者借鉴国外研究成果和结合中国国情的基 础上, 在学科建设方向、基础理论完善、研究体系构建等方面取得了很大发展, 推动了理论 研究和实践活动相互作用与促进, 形成了两者良性互动的发展局面。在新的历史时期, 中国 发展阶段特征、发展理念、发展目标、战略重点均发生了深刻变化, 更加强调尊重自然发展 规律、发挥生态多重价值、促进经济绿色转型的绿色发展。顺应新趋势、回应新需求、实现 新目标, 迫切需要丰富和完善中国特色生态经济学的理论研究内容和体系, 为推动中国生态 经济实践活动发挥更具针对性、实效性的服务与指导作用。

\section{2.中国发展新阶段拓展了生态经济学研究范畴}

1962 年和 1972 年, 美国学者 Rachel Carson 和 Donella Meadows 撰写的《寂静的春天》 《增长的极限》, 引发了人们对生态资源有限性和人类欲望无限性之间关系的理性思考, 成 
为促进世界经济发展观念转变的“导火索”。学者的理性观点和科学主张深刻影响了随后 30 年间联合国召开的“人类环境会议”“环境与发展会议”“可持续发展世界首脑会议”的主旨，充 分体现出理论发展来源实践, 又推动了实践活动的互动过程。当前, 中国发展进入新时代, 发展理念、发展方式正在深刻变化, 开启了绿色发展新征程, 为拓展中国生态经济学研究范 畴提供了现实基础。

\section{1 生态经济学研究范畴的分歧}

生态经济学研究基本范畴是生态经济系统, 即研究以生态系统与经济系统相互作用所形 成有机复合整体结构及其矛盾运动发展规律。国内外学者对此研究的侧重点、角度和方法虽 有不同, 但是研究范畴的基础共识是生态经济系统是由生态系统和经济系统构成, 而经济系 统是生态系统的子系统。目前, 学者对于社会系统在生态经济系统中的定位和作用还未形成 统一认识, 主要体现在对于社会系统是否应纳入生态经济系统进行考量, 即是否将社会系统 作为子系统纳入生态经济学的研究范畴。由此，国内外学者形成了“两维复合系统论”与“三维 复合系统论”不同观点。“两维复合系统论”强调生态经济系统是经济系统与生态系统相互作用 的复合有机体。代表学者 Herman E.Daly（2007）认为, 经济系统只是这个大的“地球系统” 的一个开放子系统, 生态经济系统是生态系统和经济系统的有机结合。沈满洪 (2004) 认为, 生态经济系统是由生态系统和经济系统通过技术中介以及人类劳动过程所构成的物质循环、 能量循环、价值增值和信息传递的结构单位和符合系统。“两维复合系统论”虽未直接提出社 会系统在生态经济系统中的定位和作用, 但也涉及到了社会系统要素如社会制度、技术载体 等在促进生态与经济系统耦合中起到的作用。“三维复合系统论”强调生态经济系统是由生态、 经济和社会三个子系统组成, 各个子系统在生态经济大系统中的定位和作用不同。王书华

(2008) 提出区域生态经济系统是以社会系统中的人为主体、以经济系统为中心、以生态系 统为基础的多功能复合系统。杨皓然（2010）认为生态经济系统是由生态、经济和社会三个 子系统构成, 其中社会子系统是联系经济和生态子系统并使两者融为一体的媒介, 为促进生 态与经济系统耦合发展提供政策和法规等保障功能。

生态经济系统研究范畴是否纳入社会子系统，不仅决定了生态经济系统的结构、矛盾和 运行方式的研究内容体系、方法工具, 也决定了研究基础、对象和目标等。虽然经济系统与 社会系统在人口、技术等方面存在一定的要素重叠, 可将重叠部分可纳入经济系统考虑, 但 是社会系统的战略设计、制度供给、价值观塑造等因素, 始终成为影响生态系统与经济系统 良性耦合发展不可或缺的重要因子, 为生态与经济系统的耦合提供着思想理念引领、制度政 策措施和体制机制保障等。因此, 社会系统的发展程度、能力和水平直接或间接地影响着生 态经济系统耦合运行的效率、效果。此种情况在中国实践中得到了更充分体现和验证。

\section{2 中国发展新阶段提出了新要求}

改革开放 40 年，中国经济粗放型增长方式在获得巨大的物质财富的同时也积累了很多 问题, 体现出对投资拉动经济依赖性较强、经济结构欠合理、自然环境承压加大、生态保护 约束不断强化等问题。面对发展新问题, 中国不断调整经济发展思路和措施, 提出经济新常 态、供给侧结构性改革等一系列重大举措, 以确保经济由高速增长阶段转向高质量发展阶段。 追求高质量,推动高质量发展成为今后一段时期中国经济发展的根本要求和新阶段特征。高质 量发展不仅强调了发展的中心主题, 也明确了经济发展与生态保护、社会进步三者的新关系。 习近平总书记更是对中国发展新阶段的生态、经济和社会相互关系提出了系统思考和观点。 他指出 “山水林田湖是一个生命共同体。如果种树的只管种树、治水的只管治水、护田的单 纯护田, 很容易顾此失彼, 最终造成生态的系统性破坏。”这段论述正是运用系统论的视角 阐明了生态、经济和社会系统中的不同主体之间的相互作用关系, 即实现健康可持续发展的 前提是生态系统、经济系统和社会系统彼此相互融合、相互协调、共生演进。换言之, 要实 
现中国可持续发展的前提是围绕生态、经济、社会的效益良性互动化, 推进经济系统发展方 式转变和加强社会系统协同管理, 以实现提升经济发展质量、促进生态代际公平、激发社会 发展动力。中国共产党第十九次全国代表大会的报告指出, 中国社会主要矛盾已经转化为人 民日益增长的美好生活需要和不平衡不充分的发展之间的矛盾。这其中, 优良的生态环境已 经成为群众生活幸福指数中重要的组成部分, 生态环境问题日益成为重要的政治问题、民生 问题、社会问题。因此, 生态问题是涉及经济和社会多领域的综合性问题, 而解决此问题需 要生态、经济和社会三者协调发展的理论支持与实践指导。

实践证明, 在中国深化改革开放过程中社会系统不断体现出强大的作用力和生命力, 成 为生态保护和经济发展的重要引擎, 形成了社会、经济和生态发展关系新模式, 用实际行动 和成效验证了社会系统在生态经济系统中具有不可或缺的地位和作用。社会系统具有自身独 特的功能和规律, 它深刻影响着生态系统与经济系统耦合、运行、交互, 体现出强大的引导 作用、保障作用、介质作用。特别是在中国新时期发展阶段，更加强调生态、经济和社会的 协调与和谐发展, 生态建设呈现新成效, 经济发展呈现新特征, 社会进步呈现新变化, 三者 间良性互动的态势正在形成。把握新阶段特征、掌握发展新规律、开创新发展格局, 需要理 论创新指导实践创新, 以适应当前中国经济、社会和生态发展的需求。基于中国发展阶段特 征, 中国生态经济学研究范畴若还仅关注生态与经济系统之间的作用关系, 淡化甚至忽视社 会系统影响作用, 必然导致研究结构和体系的欠缺, 偏离中国现阶段发展的现实要求。因此, 中国生态经济学的研究范畴应是包含了生态系统、经济系统和社会系统三者及彼此间的良性 耦合关系的生态经济系统。

\section{3.中国发展新理念拓展了生态经济学研究主题}

任何一种学科的发展都必须紧扣现实发展的主旋律。生态经济学正是由于人们认识到传 统经济社会发展对于生态环境损害的现实背景下, 寻找化解危机、破解难题、实现健康发展 而创建起来，而其研究主题也随着经济社会发展理念创新和实践创新而不断更迭。

\section{1 生态经济学研究主题的嬗变}

至今, 生态经济学研究主题经历了从生态与经济“相互关系论”“协调发展论”到两者“可持 续性论”的发展演变。20 世纪 50 年代, Prebisch、Singer 从自然资源与经济发展关系解释了 导致困境的主要原因，形成了“资源诅咒”命题，成为早期生态经济学具有代表性的成果。

Kenneth Boulding (1966) 从生态与经济两者协调发展的视角正式提出了“生态经济学”的概念 和“生态经济协调理论”, 实现了生态经济学研究主题从生态与经济彼此“诅咒”向彼此“协调” 的发展。Lester R.Brown（1981）认为人类应加强保护环境、控制经济和人口，以实现可持续 存在与发展。1990 年 5 月,第一届世界生态经济学术交流会的主旨确定为“生态经济学：可持 续性的科学与管理”，标志着可持续发展已经成为生态经济学的主流思想。Costanza（1991） 发表《生态经济学: 可持续发展的科学与管理》, 围绕“经济与生态可持续性”从多个角度论述 了生态经济学研究趋势, 在学理体系上确立了生态经济学研究的可持续主题。在国外理论和 实践影响下, 紧密结合中国发展现实国情, 中国生态经济学研究主题也走过了大致相同的变 化历程。中国生态经济学创始者许涤新 (1987) 认为人是自然的一部分, 反对人类中心主义, 强调人与自然的和谐发展。樊万选 (1994) 主编的《区域生态经济社会协调发展论》指出, 生态经济学研究的主要内容是实现生态经济社会协调发展。王松需 (2000) 在《生态经济学》 中提出, 生态经济学是为可持续发展指导思想的建立提供理论基础的科学, 也是服务于可持 续发展指导思想在中国贯彻实现的科学。刘思华（2007）出版的《刘思华可持续经济文集》 强调指出, 生态经济学寻求生态、经济两个系统之间的相互平衡与协调发展。方时蛟 (2009) 认为中国生态经济学发展与西方生态经济学主流学派的发展历程相似, 研究主题已经从生态 
经济协调论转向生态经济可持续发展论。

目前, 国内外生态经济学研究均以“可持续发展”为主题, 开展实现生态与经济协调与可 持续发展的探索。但是, 这种探索更多地关注了生态经济系统中子系统之间的相互作用关系 对生态经济系统整体性、可持续性发展的影响, 即强调了生态经济系统整体的可持续性, 而 对于生态经济系统中各个子系统实现可持续发展的主题确定、方式选择、实践措施等内容研 究较少。由于生态经济系统由生态、经济和社会子系统构成, 且不同子系统均有自己内在发 展规律和特点, 准确把握三者发展规律、发展特征和发展要求, 是实现生态经济系统可持续 发展主题的根本和基础。因此, 生态经济学“可持续发展”的研究主题明确, 但是就研究主题 的结构、内容、体系等方面还不完善、不充分, 若实现指导服务中国实践发展还需亟待完善 和丰富。

\section{2 五大发展理念丰富了新主题}

理念是理论和实践核心、灵魂，影响着理论发展方向、实践行动。党的十八届五中全会， 习近平总书记系统全面论述了“创新、协调、绿色、开放、共享”的五大发展理念，这是一场 影响中国当前和未来发展全局的深刻变革。“崇尚创新、注重协调、倡导绿色、厚植开放、 推进共享”, 凝聚着对中国经济社会发展规律的深入思考, 是我们党认识把握发展规律的不 断深化和飞跃, 丰富发展了中国特色社会主义理论体系, 成为中国发展的最新理念和思想指 引。“五大发展理念”不仅是对中国过去发展的经验总结, 更是对中国未来发展规律的科学把 握, 反应了遵循经济规律的科学发展, 遵循自然规律的可持续发展, 遵循社会规律的包容性 发展的本质, 形成了经济、生态、社会发展全局与局部、战略与战术、当前与未来有机统一 的发展新理念体系。五大发展理论既明确了生态经济系统整体发展要求, 又明确了各子系统 具体发展主题、方向和目标。因此, 中国生态经济学的研究需紧扣中国时代发展脉搏和现实 发展需要, 在尊重生态、经济、社会各自系统规律基础上关注其发展方式、发展方向、发展 路径, 从而为三者间相互作用、相互融合发展奠定坚实的研究基础, 才能为中国生态经济系 统整体性的可持续发展的实践活动做出有力的指导。

根据中国发展新理念和生态经济学研究范畴, 中国生态经济学的研究主题应在形成生态 经济系统“可持续发展”大主题下, 加强各个子系统“多元化”主题的发展格局研究, 即经济系 统的科学发展主题、生态系统可持续发展主题、社会系统包容性发展主题, 以更加切合中国 现实和学科发展规律的需要。科学发展、可持续发展、包容性发展不仅拓展了中国生态经济 学研究主题结构、内容和形式, 也使得中国生态经济学的研究方式、研究路径和研究目标更 加明确清晰, 为构建完善的研究体系指明了方向。

\section{4.中国发展新文明拓展了生态经济学研究内容}

理论来源于实践又指导实践。理论不仅是对实践活动、成果和经验的解释、概括和总结， 更是对实践进行批判性反思、规范性思考、前瞻性研判, 以充分发挥理论对实践指导、服务 的作用以及对实践超前性的科学引导。因此, 中国生态经济实践活动的宗旨任务、路径目标 均需要理论的解释、规范和引导, 这就要求生态经济理论研究的不断创新和拓展, 理论研究 才更具活力和创造力。

\section{1 生态经济学研究内容的多元}

生态经济学核心任务是解决好经济社会发展的无限性和自然资源的有限性之间的矛盾。 由于不同国家、地区的经济社会发展特点和性质的不同, 矛盾表现的内容、形式和特点也有 所不同, 使得生态经济学研究主要内容呈现动态和变化的态势。 21 世纪 60 年代至今, 国外 学者紧扣矛盾主题, 紧紧围绕着国家、地区发展现实, 开展了关于自然资源与经济发展关系、 
生态与经济系统发展、生态产权与资本等方面的研究。如, Auty（1993）关注了资源富集的 矿产国对国家经济增长的限制, 从而否定了传统经济学普遍认为资源富集可以弥补经济发展 中的资本不足或资源富集与经济发展呈现正相关等观点。Krugman（2005）认为市场中经济 活动的环境成本并不反应为市场成本, 环境成为一种社会资本, 对个人和团队造成负面影响。 中国生态经济学研究内容主要经历了从介绍西方生态经济学的理论理念、观点和方法, 到紧 密结合中国生态、经济和社会发展阶段和特点等现实问题, 不断拓展和丰富了中国生态经济 学研究体系。如, 徐康宁 (2006) 的研究成果显示, 中国在 90 年代后出现了“资源诅咒”现象, 即资源生态富裕区域阻碍了经济发展。程国栋（2009）以黑河流域为例, 从生态经济学视角 提出了生态经济综合管理的可持续发展框架。罗贵权（2015）紧密结合中国发展现实需要, 提出中国生态经济学研究内容应是深化对生态文明建设体制机制创新的研究, 以“绿色化”推 进新型工业化、信息化建设以及大力推动绿色产业等。

目前, 国内外学者生态经济学研究内容呈现多元化, 研究成果逐渐形成了百家争鸣、百 花齐放繁荣发展格局。归纳和梳理研究内容总体现出研究视角多样、研究体系独立、研究成 果丰富, 但是各研究内容和主要论点间的内在逻辑关系把握并不全面、不准确, 也未形成系 统化、体系化的研究内容框架。造成此局面的根本原因, 是由于生态经济研究内容的复杂性、 多元性、动态性而导致研究成果的相对独立甚至是割裂。解决此问题, 需要紧扣研究范畴和 主题全面结合现实发展，用更为广阔的视域、更丰富的体系构建生态经济学的研究内容。

\section{2 生态文明建设拓展了新内容}

党的十七大提出了生态文明并将其写入报告, 成为建设“和谐社会”“小康社会”的主要目 标; 党的十八大将生态文明建设纳入中国特色社会主义“五位一体”的总体布局; 十八届三中 全会又明确提出用生态文明制度体系保障生态文明建设，推进了生态文明建设的具体化进程， 顶层设计了生态文明建设的具体内容、制度和载体。2015 年, 中共中央、国务院先后印发《关 于加快推进生态文明建设的意见》《生态文明体制改革总体方案》, 构建起自然资源产权明确、 多元建设主体参与、系统完整的生态文明建设制度体系, 使得推进生态文明建设落实有了依 据和保障。2017 年, 党的十九大报告提出“建设生态文明是中华民族永续发展的千年大计”“我 们要建设的现代化是人与自然和谐共生的现代化”等重要论述, 进一步明确了中国开启生态 文明建设新时代。总结过去 10 年, 中国生态文明建设的实践活动开启了从概念提出到制度 体系、体制机制的构建进程, 实现了生态文明建设从抽象理念向具体实践、宏观规划向微观 措施的转变。梳理发展脉络、归纳发展内容、总结发展特征, 中国生态文明建设形成了“点 线面”紧密结合的大格局, 点即生态文明建设的新理念; 线即生态文明建设主题, 促进生态 经济社会可持续发展; 面即生态文明建设体系, 包含生态意识、生态行为、生态制度、生态 经济和生态环境等内容。此格局, 一方面统筹了零散、独立的研究内容和方向, 理清了理念、 目标和体系, 另一方面明确了当下理论研究重点和难点, 提出了长远与当前、宏观与微观的 研究内容要求。伴随着中国生态文明建设的深入, 不仅丰富了中国特色社会主义事业总体布 局, 而且实现了整合和统筹生态经济学理论研究内容和体系。推进生态文明建设, 无论是理 论研究还是实践活动, 不仅没有历史经验的借鉴, 还存在理论研究欠缺、指导性弱化和实践 操作依据不充分等诸多困难。因此, 中国学者应肩负起时代发展职责, 以生态文明统领生态 经济学研究内容体系, 用现实问题牵引理论方向, 用理论成果指引实践活动, 使理论与实践 相得益彰、融合发展。

理论研究不能脱离现实发展, 学术研究为现实服务才是上乘的研究, 否则容易成为空中 楼阁的说辞, 失去理论根本的价值。中国经济社会发展的新理念新思想新战略, 需要生态经 济学者不断拓展研究体系, 丰富研究方法, 夯实研究基础, 推动生态经济学学科建设和生态 经济实践活动的互动发展。此时, 理论研究成果才具有了活力和生命力, 中国生态经济学也 


\section{才具有了中国特色和时代特征。}

\section{致谢}

论文为 2019 年中共青海省委党校重点智库课题《生态文明在青海的实践》阶段性成果。

\section{作者简介}

杨皓然，45，汉族，教授、经济学博士，青海省委党校。研究方向：生态经济学

\section{References}

[1] Wangsongpei, Chiweiyun. Utilization of natural resources and ecological economic system[M]. Beijing: China environmental science press, 1992.

[2] Shengmanhong. Ecological Economics [M]. Beijing: China environmental science press, 2008.

[3] Tangjianrong. Ecological Economics[M]. Beijing: Chemical industry press, 2004.

[4] Yanghaoran. Research on sustainable development of qinghai plateau ecological and economic system[M]. China social sciences press, 2014.

[5] Gaolehua, Gaoqiang, Shilei. Research on the coordinated development model of Marine ecological economic system in China[J]. Ecological economy, 2014, 30(2):14-17.

[6] Zhanghongfeng. The internal mechanism and countermeasures of environmental and economic regulation[J]. Study of financial issues, 2008, (3): 58-60.

[7] Xukangning, Wangjian. A study on the relationship between the abundance of natural resources and the level of economic development[J]. Economic research.2006, 41(1):78-89.

[8] Wangshuhua. Regional eco-economic system - theory, method and practice[M].Beijing: China development press.2008.

[9] Chengguodong. Study on integrated management of water - ecology - economy system in heihe river basin[M]. Beijing: Science Press.2009.

[10] Costanza, R d'Arge R, De Groot R. et al. The value of the world's ecosystem services and natural capital[J]. Nature,1997,387:253-260.

[11] Herman E.Daly \& Joshua Farley. Ecological Economics - Principles and Applications[M]. Henan: Yellow River conservancy publication, 2007.

[12] Prebisch, R. Commerical Policy in the undevelopment countries [J]. The American Economic Review.1950, 49(2): 251-273.

[13] Singer, H. Foreign Investment in Underdeveloped Areas: The Distribution of Gains between Investing and Borrowing Counties[J]. The American Economic Review.1950,40(5):473-485.

[14] Lester R. Brown. Eco-Economy: Building an Economy for the Earth[M]. Washington D C: Earth Policy Institute.2001.

[15] Auty R.M. Industrial policy reform in six large newly in-dustrializing countries: The resource curse thesis[J]. World Development, 1994, (22): 11-26.

[16] Sachs J,Warner A.The Curse of Natural Resources[J].European Economic Review ,2001,(45):827-838. 